\title{
Fast slide preparation for thrips (Thysanoptera) routine identifications
}

\author{
Luis C.P. SILVEIRA ${ }^{1}$ and Marcelo M. HARO ${ }^{2}$ \\ ${ }^{1}$ Universidade Federal de Lavras (UFLA), Departamento de Entomologia (DEN), P.O. Box 3037, CEP 37200-000, Lavras, MG, \\ Brazil; e-mail: Icpsilveira@den.ufla.br \\ ${ }^{2}$ Agricultural Research and Rural Extension Agency of Santa Catarina (EPAGRI), Itajaí Experimental Station (EEI), CEP 88318- \\ 112, Itajaí, SC, Brazil; e-mail: marceloharo@epagri.sc.gov.br
}

Key words. Thysanoptera, Thripidae, Phlaeothripidae, pest, IPM, Hoyer's solution, slide mount, identification

\begin{abstract}
Thrips are important agricultural pests and accurate identification is important for their effective management. In order to determine species, however, they need to be mounted on slides and the traditional process is time-consuming. The aim of this paper is to describe a simple and fast method to prepare temporary slides for the routine identification of thrips, which is not dependent on their colour and hardness. Four species of thrips of different colours were used in the preparations: Frankliniella occidentalis (yellow with brown tergal markings), Frankliniella schultzei (entirely brown), Haplothrips gowdeyii (dark brown to carmine) and Caliothrips phaseoli (brown to black). Slides of each species were prepared using three different methods: traditional ( 3 days), simplified $(6 \mathrm{~h})$ and fast method $(10 \mathrm{~min})$. The thrips on the resulting slides were observed under a microscope and important structures used in their identification were compared. The quality of the slides prepared using the traditional method was superior to those prepared using the other two methods if only the transparency and general position of the insects on the slides were considered. The transparency of the slides prepared using the simplified method was also good, but only for the pale coloured species (yellow and grey-brown). The fast method, on the other hand, was very efficient for routine identification since it resulted in slides of sufficient quality for identifying species regardless of their colour. It is important, however, to stress that the fast method is only suitable for preparing temporary slides for routine identification and is not a substitute for the traditional method of preparing permanent slides.
\end{abstract}

\section{INTRODUCTION}

Many thrips (Thysanoptera) are important pests of horticultural and ornamental crops, causing damage directly by ovipositing and feeding (Mound, 2005; Reitz, 2009; Ripa et al., 2009; Bosco \& Tavella, 2010) and indirectly also as vectors of important plant viruses (Deavila et al., 1993). Frequently the presence of thrips disrupt IPM (Integrated Pest Management) programs as they can only be controlled using chemicals (Weiss et al., 2009) and many species are resistant to common insecticides (Morse \& Hoddle, 2006; Bielza, 2008). Thrips are small insects, and in general are difficult to see when inspecting plants because of their cryptic habits, which enable them to colonize plants and habitats undetected (Kirk, 2007).

Determining which species of pest is damaging a crop is the foundation of all IPM decisions (Kogan, 1988) and so the correct identification of thrips is important in their management. This is particularly the case for the Thysanoptera, as their presence on a crop does not necessarily imply a pest problem, as only one percent of the species of thrips are economically important pests (Parker, 1995; Monteiro, 2001). Nevertheless, their correct identification depends on preparing slides, which can be used for identification by specialists based on a study of their morphological characters under a microscope or by the use of cybertaxonomic tools (Fedor et al., 2014). The traditional process of preparing slides of thrips is well described (Mound \& Kibby, 1998) and was developed for archiving and taxonomic research, using a permanent mountant (Canada Balsam) and a process that maintains the shape and colour of the specimens as close to natural as possible. The only disadvantage of this method is that it is time-consuming since it takes at least three days to produce a slide suitable for study.

Collections of thrips from plants frequently include many species and sometimes large numbers individuals, which makes the traditional method impractical as many slides are needed to ensure that all the specimens are correctly identified. For this reason many researchers use a simpler method (Mound \& Kibby, 1998), which takes only one day, to prepare slides for routine identification using a water-soluble mountant (Hoyer's). There are also other similar methods (Bisevac, 1997). These temporary slides are far easier to prepare but are not suitable for dark coloured species or those with hard bodies. So an alternative quick method for preparing slides of dark/hard bodied specimens is still needed.

It is important to stress, however, that the slides obtained using these simple methods are only temporary and not a substitute for permanent slides. Upton (1993) reports that many microscope slides of important arthropod species in museums were lost because they were temporary preparations, especially those that were mounted in gum Arabic and chloral hydrate (the proportions varied greatly over time), and appropriate permanent slides were never prepared. 
The purpose of this study is to describe a simple and fast method for preparing temporary slides for the routine identification of thrips, independent of their colour and hardness. Four differently coloured species of thrips were selected to compare the different methods. The best slides prepared using each of the three methods were selected and compared using a microscope in order to determine the best method.

\section{MATERIAL AND METHODS}

Four species of differently coloured thrips were used to compare the three methods: Frankliniella occidentalis (Pergande, 1895), yellow with brown tergal markings; Frankliniella schultzei (Trybom, 1910), entirely brown; Haplothrips gowdeyi (Franklin, 1908), dark brown to carmine; Caliothrips phaseoli (Hood, 1912), dark brown to black.

The processes of maceration, dehydration, diaphanization and mounting thrips on slides used in the three different methods are described below.

a) Slide preparation for archiving and taxonomic research: the traditional process (Mound \& Kibby, 1998).

b) Slide preparation for routine identification: the simplified method (Mound \& Kibby, 1998). This method is much faster than the traditional one and can be done in less than one day, but is only suitable for pale species and temporary preparations, and therefore the authors do not recommend its use for other applications.

c) Fast slide preparation for routine identification: the fast method described in this paper. This method is based on the other two but some steps were eliminated or heating was used to accelerate the process. The specimens, independent of whether they were kept in 60 or $70 \%$ alcohol, AGA or other collecting fluid, were placed in a watch-glass with $5 \% \mathrm{NaOH}$ or $\mathrm{KOH}$. The abdomen was then punctured between the hind coxae with a fine needle and subsequently the specimen gently massaged to expel some of the body contents. The watch-glass is then suspended and heat is applied via an alcohol lamp or similar heat source, for a short time (20-30 s). Heating time needs to be rigorously adhered to due to the risk of destroying a sample. The watchglass is moved to a stereomicroscope and the specimen is massaged gently while evaluating its transparency. If necessary, this treatment in $\mathrm{NaOH}$ or $\mathrm{KOH}$ can be repeated up to three times for dark coloured specimens. When the specimen is considered to be sufficiently transparent, it is placed in a test tube with a small volume of clarifying solution, consisting of lactic acid $85 \%$ (20 parts), glacial acetic acid (4 parts), phenol (2 parts) and distilled water (1 part). The test tube was then heated in the same way as before until the liquid in the tube started to circulate, which takes between 20 and $40 \mathrm{~s}$ depending on the volume of clarifier utilized in the tube. For pale specimens, one circulation of the liquid is enough and for the darkest specimens two or at most three circulations of liquid are needed, but it should be born in mind that excessive heating at this stage in the process can damage the specimen. After this, the specimen is cleared by transferring it to a watch-glass containing a few drops of warm clove oil for $20 \mathrm{~s}$. The specimen is mounted in Hoyer's solution exactly as in the other two methods. If when examined under a microscope the specimen is not sufficiently transparent heat is applied to the underside of the slide just below the specimen for several seconds and repeated if necessary.

Individuals of each species were prepared using each of these methods and the best slides were photographed under a microscope. Some of the body structures of the individuals prepared using each of these methods were used to identify them using identification keys (Mound \& Marullo, 1996; Mound \& Kibby, 1998).
Photographs of the entire body of individuals prepared using each of these methods were taken of specimens of which the wings, legs and antennae were in their natural positions, since this enables one to observe other characteristics.

For the species $F$. occidentalis and $F$. schultzei the structures selected were the position of the ocellar setae III in relation to the ocellar triangle (only for F. shultzei), presence or absence of the campaniform sensilae on metanotum and size and appearance of the teeth on the posteromarginal comb of VIII tergite. For F. occidentalis only, the presences of brown marks on the urosternites were also photographed.

For H. gowdeyi, the following characteristics were photographed: the maxillary stylets retracted inside the head and the maxillary bridge; shape of the basantra inside the probasisternum and the two pairs of wing-retaining setae on the abdominal tergites. The structures used to compare the individuals of $C$. phaseoli prepared using each of these methods were the pattern of light and dark bands on the wings, the reticulate sculpture within each of the reticules on the pronotum, the striae on the metanotum and the sculpture on the lateral thirds of abdominal tergites.

\section{RESULTS AND DISCUSSION}

Results are illustrated in Figs 1, 2 and 3.

Time needed to produce a slide depended on the number of steps in each of the methods. The traditional process (Mound \& Kibby, 1998) took two and a half to three days of preparation and several weeks of drying in an oven, the simplified method (Mound \& Kibby, 1998) required one to two minutes preparation and $6 \mathrm{~h}$ drying in an oven; and it took $10 \mathrm{~min}$ to produce a slide using the fast method.

The general appearance of the thrips on the slides produced using the three methods differed slightly (Fig. 1). The photographs of the individuals on slides of all four species prepared using the traditional method were slightly better for identification in terms of the general position of the specimen, especially the arrangement of the wings, antennae and legs. Insects prepared using the simplified and fast methods were also suitable for identification as at least the appendages on one side of the body were well positioned, as can be seen in Fig. 1 B3, C3 and D3.

Particular steps during the preparation of specimens determined the different times required to complete the mounting of the thrips on slides using the different methods. The traditional method involved extensive handling of specimens, such as thorax and abdomen massaging, repositioning of wings, legs and antennae and eight exchanges of solutions during the maceration and dehydration process. All of this required high technical ability in order to prevent damage to important structures used for identifying the specimens.

The simplified method proposed by Mound \& Kibby (1998) required less time than the traditional method, as the slides were prepared in two minutes and a further $6 \mathrm{~h}$ were required for drying in an oven. Furthermore, the specimens are less likely to be damaged using this method as the solution is only changed once, which reduces the number of manipulations.

However, the fast method of producing slides took only five to $10 \mathrm{~min}$ since the time spent in an oven was replaced by direct heating, which decreased the time required considerably compared to the other methods, but nevertheless resulted in slides suitable for routine identification.

In terms of the technical competence required the simpler method was the simplest, followed by the fast and then the traditional method. The simpler method is suitable for pale species and requires fewer steps, which makes it more accessible (Mound \& Kibby, 1998). 


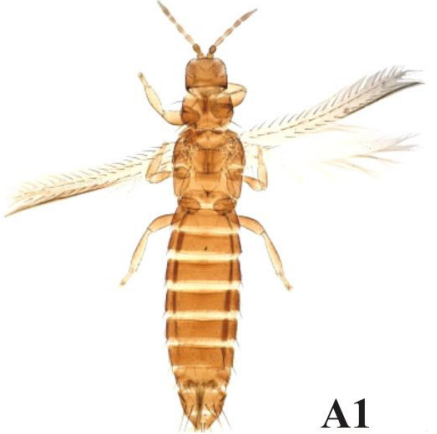

A1
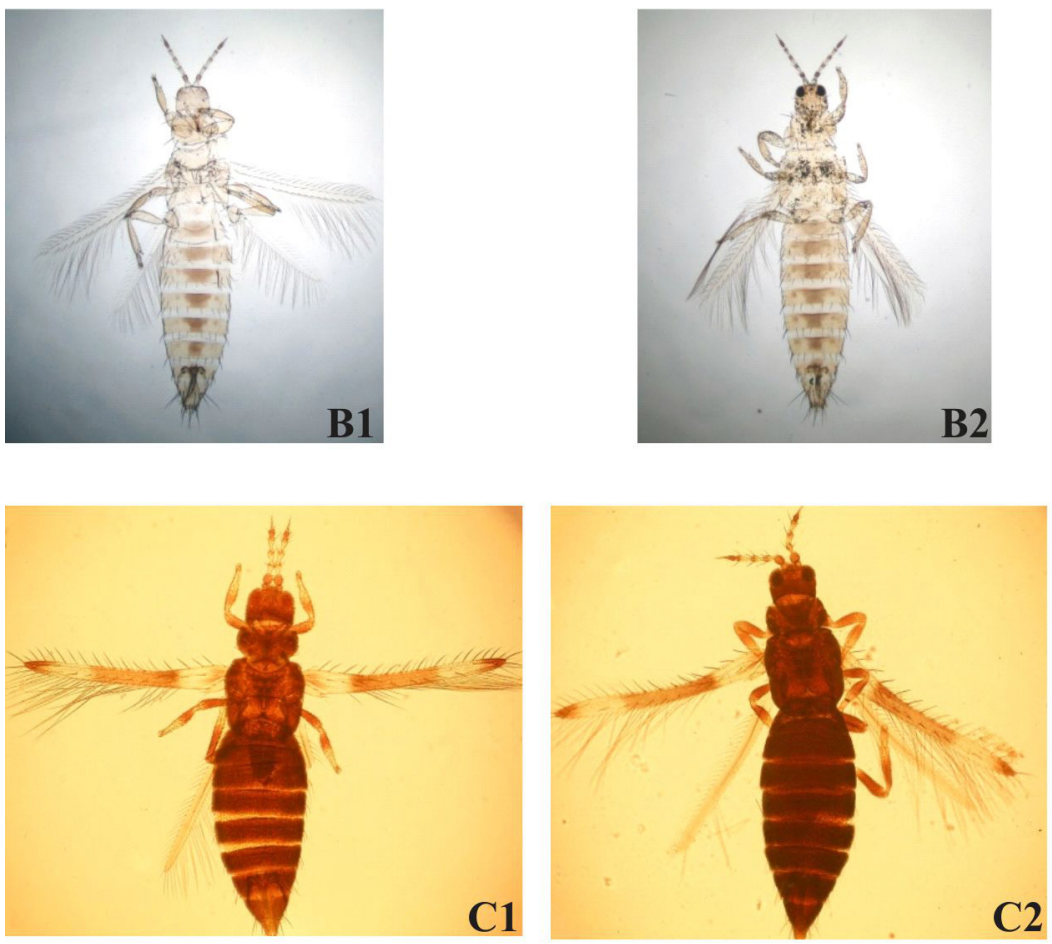

A2
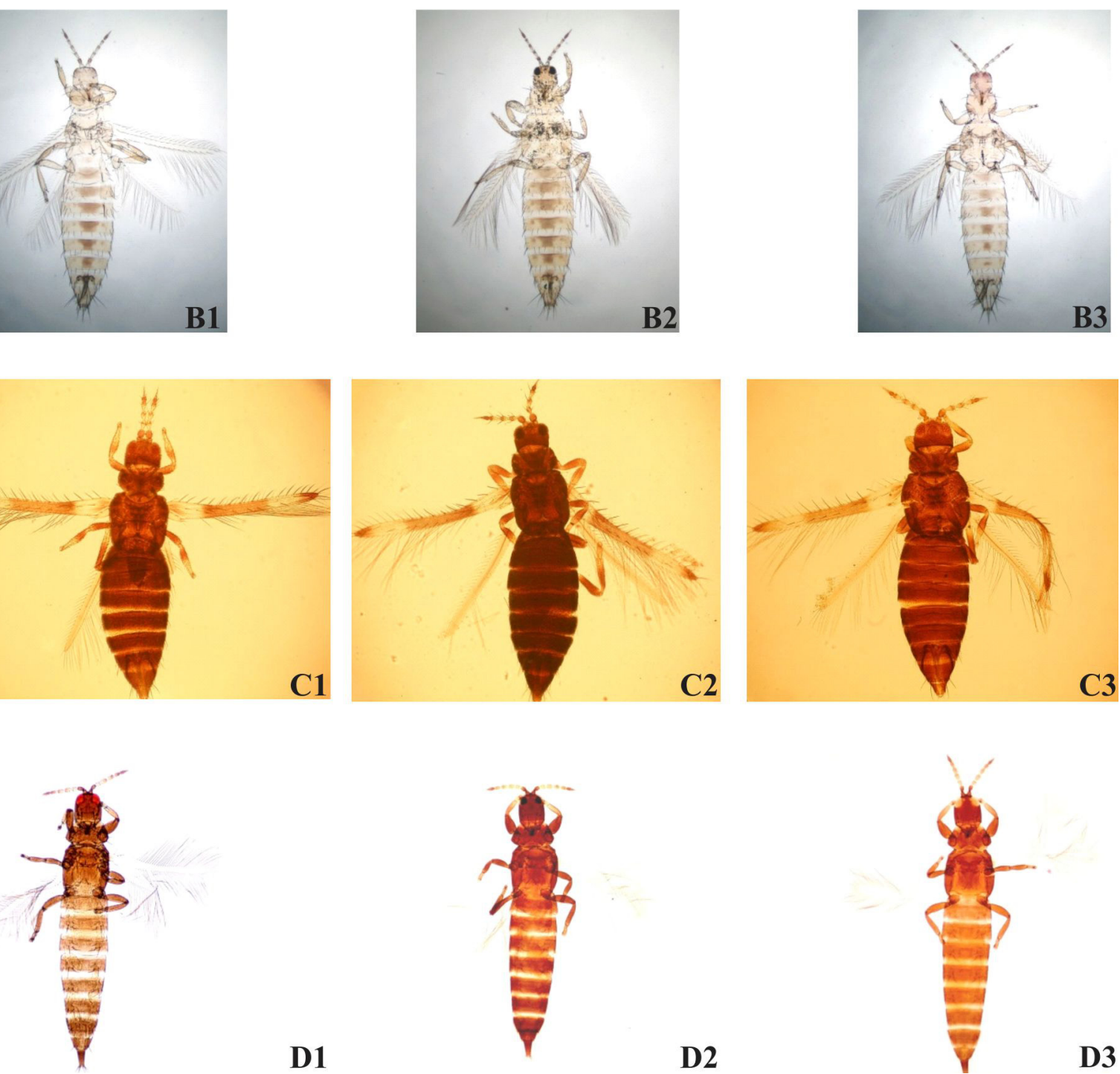

D1

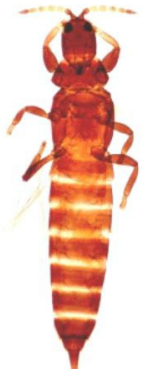

D2

Fig. 1. Photographs of slides of four species of thrips prepared using three different methods. A - F. schultzei; B - F. occidentalis; C $-C$. phaseoli; D - H. gowdeyii. Methods used: 1 - traditional; 2 - simplified; 3 - fast.

Regarding the arrangement of the specimen on the slides the best results were obtained using the traditional method, with body, wings, legs and antennae well positioned (Fig. 1). Satisfactory results were obtained using the other two methods, although it was not possible to correct the arrangement of the appendages of the specimen (Fig. 1 A2, B3, C2 and D3). These specimens were still suitable for identification since only one leg or wing in its correct position is required. Furthermore, the practicality of the rapid methods makes it possible to prepare more slides with the positioning of key features for identification generally satisfactory. In addition, the level of technical skill required is low.

For evaluating the taxonomical structures used for identifying the four species used, the simplified method was the most satisfactory in terms of the transparency of the pale species $F$. schultzei and $F$. occidentalis, although some crystals formed in the bodies of the specimens. These crystals, however, did not obscure important structures and characteristics used in their identification. The incidence of crystallization can be reduced by changing the 

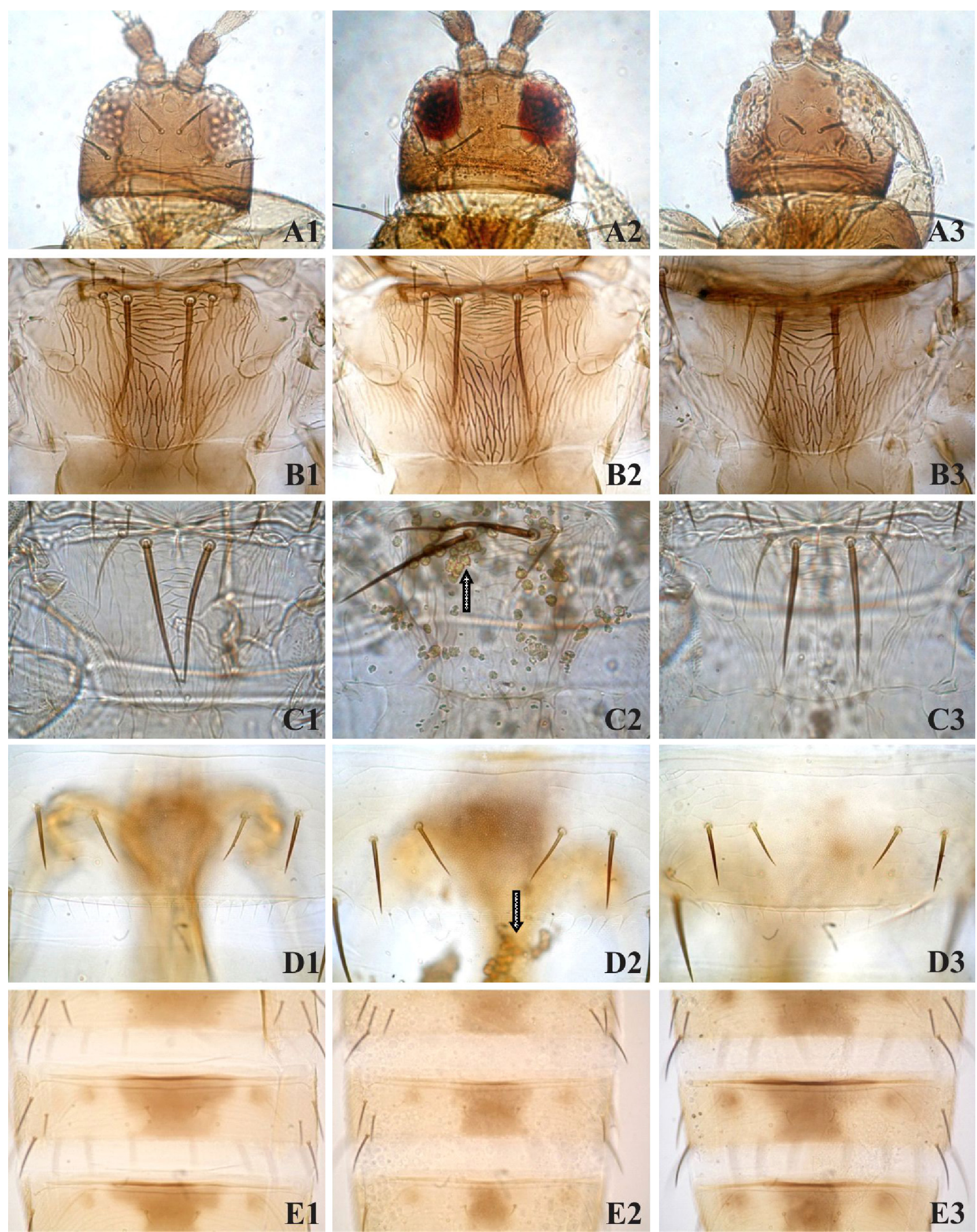

Fig. 2. Photographs of selected taxonomical characteristics of thrips on slides prepared using three different methods. A - position of the ocellar setae III; B - absence of campaniform sensilae on metanotum (F. schultzei); C - presence of campaniform sensilae on metanotum; D - teeth on the posteromarginal comb on VIII tergite; $\mathrm{E}$ - presence of brown marks on the urosternites (F. occidentalis). Methods used: 1 - traditional; 2 - simplified; 3 - fast.

concentration of Hoyer's solution, or improving the filtering process (Upton, 1993). The limitation of the simplified method was the visualization of the structures needed for the identification of the darker species (Fig. 3, number 2), as reported by Mound \& Kibby (1998). 

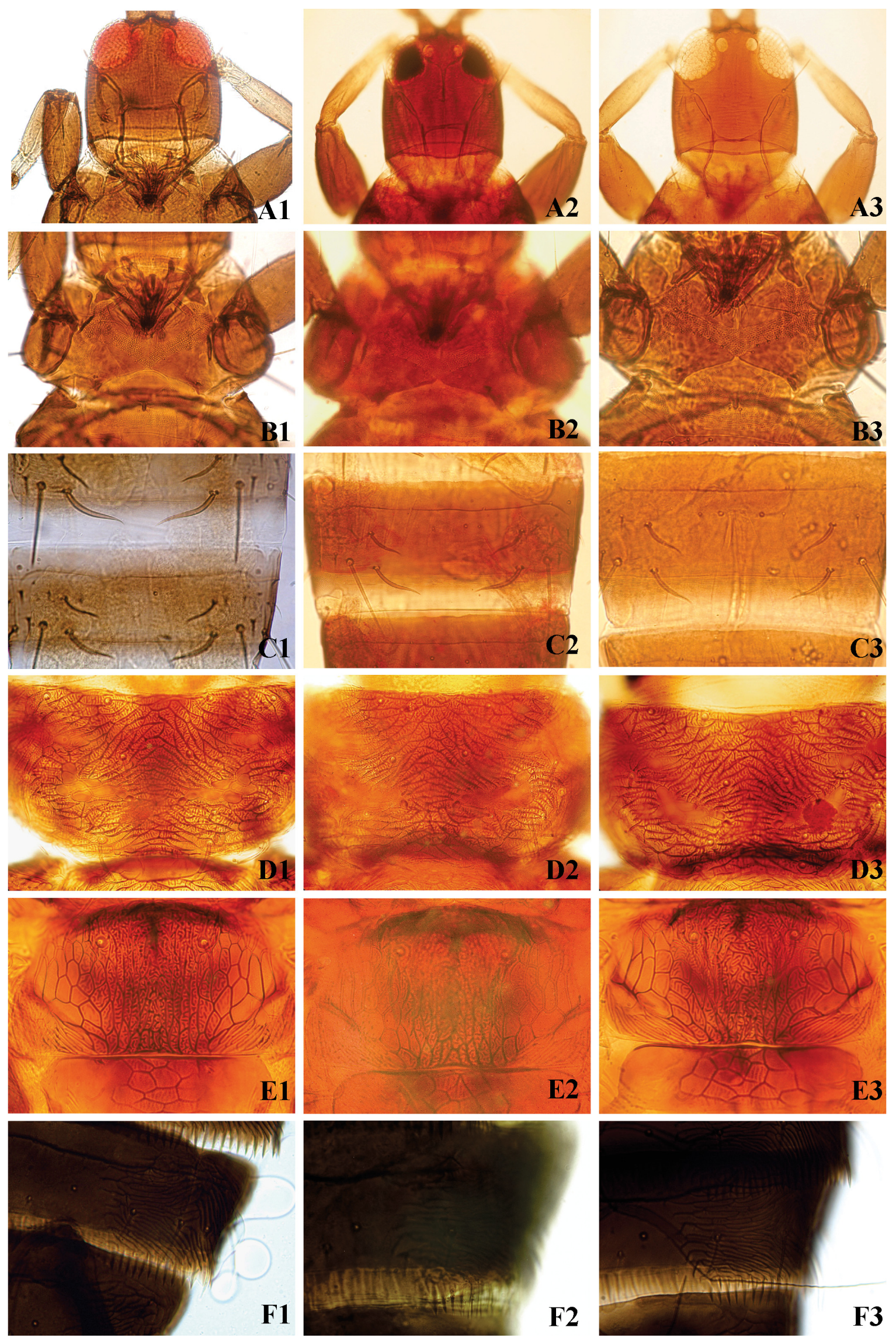

Fig. 3. Photographs of selected taxonomical characteristics of thrips on slides prepared using three different methods. A - maxillary stylets retracted inside the head; B - shape of the basantra inside the probasisternum; C - presence of two pairs of wing-retaining setae on abdominal tergites (H. gowdeyii); D - the reticules on the pronotum; $\mathrm{E}$ - striae on the metanotum; F - sculpture on the lateral thirds of abdominal tergites (C. phaseoli). Methods used: 1 - traditional; 2 - simplified; 3 - fast. 
The best results were obtained using the traditional and fast methods, which resulted in similar transparency and visual quality of all characters and structures independent of the colour of the species (Figs 2 and 3).

Considering the time required and slide quality, the fast method was the most satisfactory for both pale species (Fig. 2, number 3) and dark species (Fig. 3, number 3), and provided similar results to the traditional method (Figs 2 and 3, number 1). It was even possible to see structures such as the reticulate sculpture on the pronotum and metanotum, and sculpture on the edges of abdominal tergites (Fig. 3 D3, E3 and F3 respectively), even in dark species such as $C$. phaseoli in slides prepared using the fast method. Similar quality slides were obtained for other dark species, such as H. gowdeyii (Fig. 3, A3, B3 and C3).

It took significantly less time to produce satisfactory slides without crystals of pale species using the fast method (Fig. 2) than by using routine traditional methods.

The slides produced by the three methods used in this study were suitable for identifying thrips. As outlined above the routine and fast methods are suitable for identifying known species but not for describing new species, which requires the preparation of permanent slides with perfect body positioning.

Considering only the quality of slides, the best results were obtained using the traditional method for all the species tested (Fig. 1,2 and 3). However, if for normal identification time is a limiting factor, the routine method is recommended for pale species, but care should be taken to avoid crystal formation, and the fast method for pale and dark species.

ACKNOWLEDGEMENTS. The authors would like to thank A. Campbell (Lancaster University, UK) for editing the English. We also want to express our special thanks to FAPESC, FAPEMIG, CAPES e CNPq for the scholarship and financially supporting this study.

\section{REFERENCES}

BIELZA P. 2008: Insecticide resistance management strategies against the western flower thrips, Frankliniella occidentalis. - Pest Manag. Sci. 64: 1131-1138.

BisevaC L. 1997: A new method for mounting thrips (Thysanoptera) on slides. - Austr. J. Entomol. 36: 220.

Bosco L. \& TAVella L. 2010: Population dynamics and integrated pest management of Thrips tabaci on leek under field conditions in northwest Italy. — Entomol. Exp. Appl. 135: 276-287. de Ávila A.C., de Haan P., Kormelink R., Resende R.D., GoldBACH R.W. \& Peters D. 1993: Classification of tospoviruses based on phylogeny of nucleoprotein gene-sequences. $-J$. Gener. Virol. 74: 153-159.

Fedor P., Peña-Mendéz E.M., Kucharczyk H., VañHara J., Havel J., DoričovÁ M. \& Prokop P. 2014: Artificial neural networks in online semiautomated pest dicriminability - an applied case of 2 Thrips species. — Turk. J. Agric. Forest. 38: 111-124.

KIRK W.D. J. 2007: The chemical language of thrips. - J. Insect Sci. 7: 1-17.

KogAN M. 1988: Integrated pest-management theory and practice. - Entomol. Exp. Appl. 49: 59-70.

Mercet R.G. 1912: Los enemigos de los parasitos de las plantas. - Trab. Mus. Nac. Cienc. Nat. 10: 36-39.

Monteiro R.C. 2001: The Thysanoptera fauna of Brazil. In Mound R.M.L. (ed.): Proceedings of the 7th International Symposium on Thysanoptera, Reggio, Calabria, Italy, 2-7 July, 2001. CSIRO Entomology, Canberra, pp. 325-340.

Morse J.G. \& Hoddle M.S. 2006: Invasion biology of thrips. Annu. Rev. Entomol. 51: 67-89.

Mound L.A. 2005: Thysanoptera: Diversity and interactions. Annu. Rev. Entomol. 50: 247-269.

Mound L.A. \& KibBy G. 1998: Thysanoptera: An Identification Guide. 2nd ed. CSIRO Entomology, Canberra, 70 pp.

Mound L. \& Marullo R. 1996: The Thrips of Central And South America: An Introduction (Insecta: Thysanoptera). Memoirs on Entomology International, Florida, 488 pp.

PARKer B.L. 1995: Thrips biology and management. In Parker B.L., Skinner M. \& Lewis T. (eds): Proceedings of the 1993 Conference on Thysanoptera, Towards Understanding Thrips Management, Burlington, VT, USA, 1993. Plenum, New York, pp. 41-346.

REITZ S.R. 2009: Biology and ecology of the western flower thrips (Thysanoptera: Thripidae): the making of a pest. - Fla Entomol. 92: 7-13.

Ripa R., Funderburk J., Rodriguez F., Espinoza F. \& Mound L. 2009: Population abundance of Frankliniella occidentalis (Thysanoptera: Thripidae) and natural enemies on plant hosts in central Chile. - Environ. Entomol. 38: 333-344.

Upton M.S. 1993: Aqueous gum-chloral slide mounting media an historical review. - Bull. Entomol. Res. 83: 267-274.

Weiss A., Dripps J.E. \& Funderburx J. 2009: Assessment of implementation and sustainability of integrated pest management programs. — Fla Entomol. 92: 24-28.

Received April 4, 2016; revised and accepted May 10, 2016 Published online June 1, 2016 